\title{
STUDIES OF HEMOPHILIA. II. THE ASSAY OF THE ANTIHEMOPHILIC CLOT-PROMOTING PRINCIPLE IN NORMAL HUMAN PLASMA WITH SOME OBSERVATIONS ON THE RELATIVE POTENCY OF .CERTAIN PLASMA FRACTIONS ${ }^{1}$
}

\author{
BY BENJAMIN ALEXANDER AND GRETA LANDWEHR \\ (From the Medical Research Laboratory, Beth Israel Hospital, and the Department of Medicine, \\ Harvard Medical School, Boston)
}

(Received for publication June 25, 1947)

Ever since Sahli (1) demonstrated that the coagulation of hemophilic blood is accelerated by the addition of normal blood ${ }^{2}$ many workers ( 2 to 9) have focused attention on its clot-promoting property. Since cell-free plasma seemed as effective as platelet-rich plasma this action could not be directly attributed to any of the cellular components of blood (2). Hemophilic plasma ws found to be inert.

The antihemophilic factors in normal plasma seem to be associated with the globulins and fibrinogen (3 to 7), and appear preponderantly in Fraction I obtained by Cohn and his collaborators $(7,10$ to 12$)$.

The present communication deals with the quantitative relationship between the amount of normal plasma added to hemophilic blood and the coagulation time of such mixtures. We believe that the observations provide a basis for estimating antihemophilic activity of plasma, and we present them in the hope that they will be extended by others in studies of the coagulation defect of hemophilic blood. Also included are some observations on the potency of certain plasma fractions, which demonstrate the applicability of the relationship to work aimed at the separation of the clot-promoting principle from plasma.

\section{METHOD}

Five hemophiliacs were studied, 4 adults and 1 . child. The clinical manifestations and laboratory tests conformed entirely with a diagnosis of hemophilia.

Coagulation times were determined by a modification of the Lee and White method (13). No determination was considered valid unless the hemophiliac's vein was entered directly with the first puncture and blood flowed readily into the syringe.

1 Presented in abstract form before the American Society. for Clinical Investigation at its annual meetings in 1946 and 1947.

2 Except where otherwise indicated, the term "normal" will refer to "non-hemophilic."
Normal plasma was obtained by adding 9 parts (by volume) of venous blood, drawn under stasis, to 1 part (by volume) of 2.5 per cent sodium citrate solution, centrifuging the mixture promptly at 2000 r.p.m. for $10 \mathrm{~min}$ utes, and removing the supernatant citrated plasma. Serial dilutions were prepared immediately before testing by diluting with a volume of physiological saline sufficient to contain the desired amount of plasma to be tested in $0.1 \mathrm{cc}$. of the diluted mixture This was pipetted into the clotting-time tubes previously rinsed with physiological saline, 2 cc. of freshly drawn hemophilic blood were added, and the coagulation times were recorded.

\section{OBSERVATIONS}

Clotting time of hemophilic blood mixed in vitro with varying amounts of normal plasma

The coagulation of hemophilic blood added to minute amounts of normal plasma was accelerated to a degree which depended on the relative amount of normal plasma in the mixture (Figure 1). Although this reaction was uniform for all the patients studied, each hemophiliac exhibited a pattern peculiar to himself.

When the logarithm of the clotting time was plotted against the logarithm of the amount of normal plasma added to $2 \mathrm{cc}$. of hemophilic blood a linear relationship was obtained (Figure 2) which, in 3 hemophiliacs who were thus studied, was relatively constant over a period of from 10 to 23 months of observation, despite the fact that these subjects had been receiving plasma infusions 3 to 4 times weekly as prophylactic therapy (14).

Plasma from different individuals (Table I) or from the same individual at different times vary somewhat in antihemophilic activity. In 46 nonhemophilic plasmas ${ }^{3}$ tested on the blood of the same hemophiliac over a period of 15 months the

\footnotetext{
3 Comprising fresh or freshly processed frozen plasmas from normal male and female subjects and from patients with anemià, polycythemia, myocardial infarction, cancer, infections.
} 


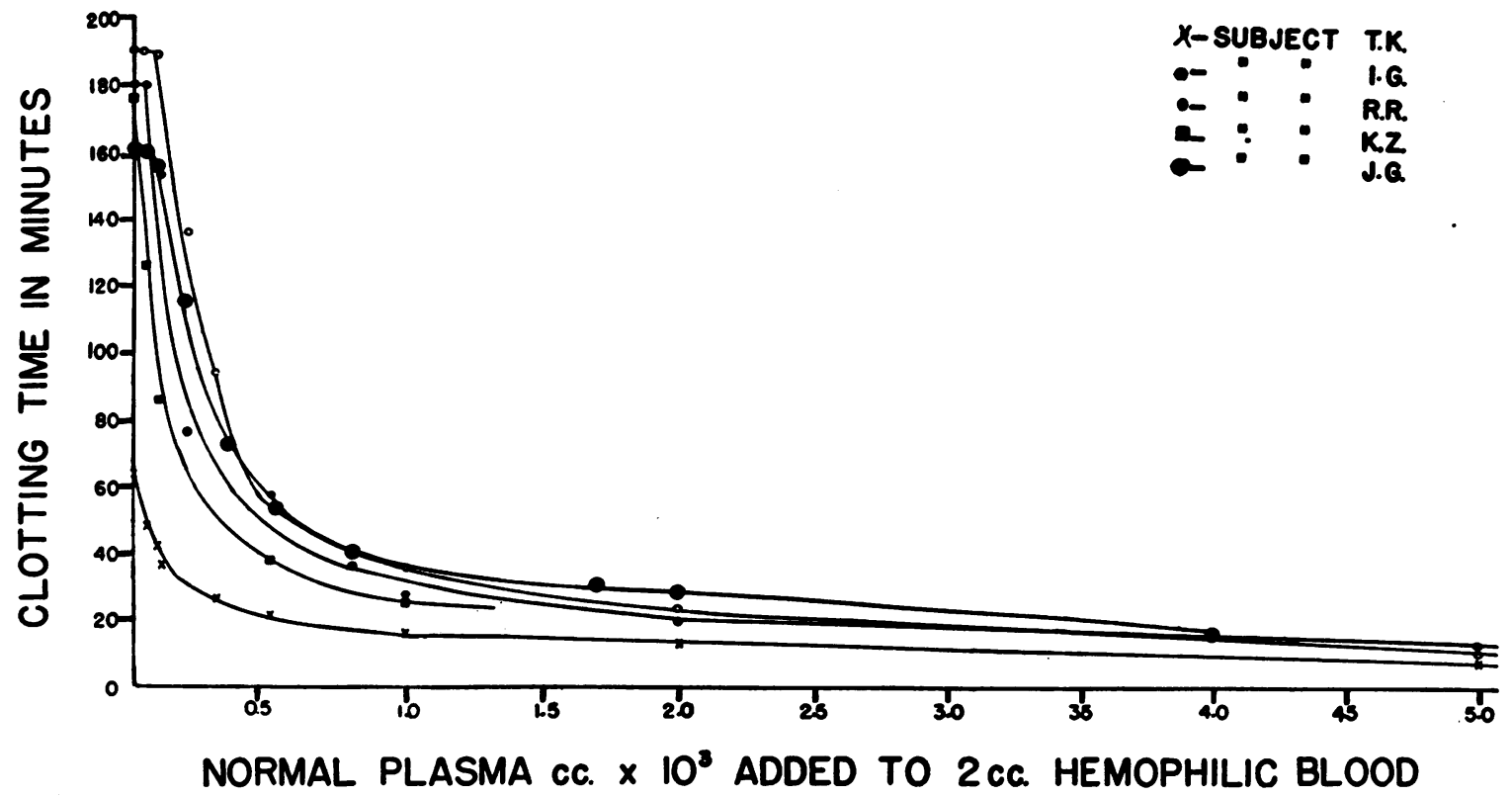

Fig. 1. Relationship between the Amount of Normal Citrated Plasma Added in vitro to Hemophilic Blood and the Coagulation Time of the Mixture

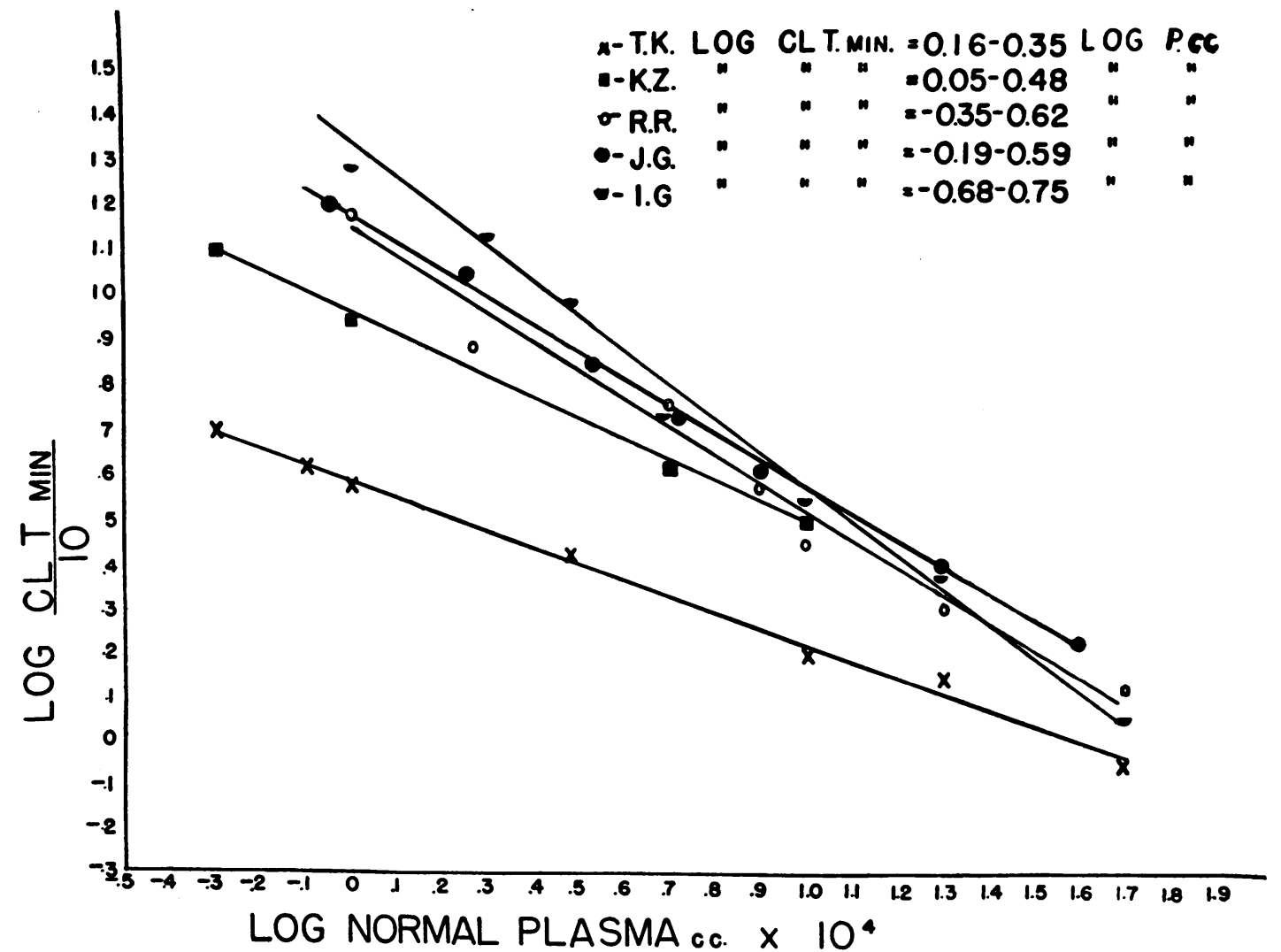

Fig. 2. Logarithmic Plot of Relationship Presented in Figure 1 
TABLE I

Effect of normal plasma from different individuals on coagulation time of hemophilic blood

\begin{tabular}{cc}
\hline & Clotting time (min.) after addi- \\
tion of plasma to 2 cc. \\
hemophilic blood \\
Subject & Amount of plasma added \\
S.001 cc. & $0.0005 \mathrm{cc}$. \\
\hline
\end{tabular}

Experiment 1

Hemophilic T. K. Control Cl. T., $65 \mathrm{~min}$.

$\begin{array}{llll}\text { Mr. Sp. } & 0 \rightarrow & 16.5 & 23 \\ \text { Mr. Sh. } & 0 \rightarrow & 16.5 & 21 \\ \text { Mrs. R. } & 0+ & 17.5 & 23\end{array}$

Experiment 2

Hemophilic R. R. Control Cl. T., $64 \mathrm{~min}$.

G. L.

$\underset{0 \rightarrow}{0+}$

30

\begin{tabular}{lll} 
& 28 & 36 \\
\hline
\end{tabular}

Experiment 3

Hemophilic T. K. Control Cl. T., $34 \mathrm{~min}$.
G. L.
$\underset{0 \rightarrow}{0+}$
14.5
19.5
B. A.
17.5
21.0

Experiment 4

Hemophilic T. K. Control Cl. T., 33 min.

$\begin{array}{llll}\text { Miss I. } & 0+ & 17.0 & 24.5 \\ \text { Dr. Hu. } & 0 \rightarrow & 16.5 & 24.0 \\ \text { Dr. Ho. } & 0 \rightarrow & 19.0 & 26.0 \\ \text { Miss W. } & 0+ & 17.5 & 24.5\end{array}$

Experiment 5

Hemophilic I. G. Control Cl. T., $42 \mathrm{~min}$.

Mr. Sh.

$\stackrel{0 \rightarrow}{0 \rightarrow}$

19

27

Mr. G.

21

29

potency was fairly uniform with a standard deviation of 0.3 unit in terms of a mean activity of 1.0 unit.

Correlation between the original coagulation time, clotting time induced by addition of normal plasma, and the clinical severity of the hemophilia

There seemed to be some degree of correlation between the clinical severity of the hemophilia and the slope of the relationship shown in Figure 2. Thus T. K. (original clotting time $70 \mathrm{~min}$.) with a slope of -0.35 , was the mildest hemophiliac (had suffered the least crippling hemorrhages) of our series, whereas I. G. (original clotting time 190 minutes) with a slope of -0.75 , was the worst. R. R. and J. G. (original clotting times 180 and 170 to 200 minutes, respectively) with slopes of -0.62 and -0.59 were moderately severe hemophiliacs clinically.
TABLE II

Assay of antihemophilic potency of Fraction $I^{*}$ obtained from human plasma

\begin{tabular}{|c|c|c|c|c|c|c|c|}
\hline $\begin{array}{l}\text { Test } \\
\text { sub- } \\
\text { ject }\end{array}$ & $\begin{array}{l}\text { Orig. } \\
\text { cl. t. }\end{array}$ & $\begin{array}{l}\text { Lot } \\
\text { No. }\end{array}$ & $\begin{array}{l}\text { Amt. } \\
\text { added } \\
\text { to } 2 \text { cc. } \\
\text { hem. } \\
\text { bl. }\end{array}$ & $\begin{array}{c}\text { Final } \\
\text { cl. t. }\end{array}$ & $\begin{array}{c}\text { Ex- } \\
\text { pected } \\
\text { cl. t. } \\
\text { with } \\
\text { normal } \\
\text { plasma }\end{array}$ & $\begin{array}{l}\text { Antihemophilic } \\
\text { activity in per } \\
\text { cent of that in } \\
\text { an equivalent } \\
\text { amount of } \\
\text { normal plasma }\end{array}$ & $\begin{array}{l}\text { Average } \\
\text { anti- } \\
\text { hemo- } \\
\text { philic } \\
\text { activity }\end{array}$ \\
\hline T. K. & $\min$. & $\begin{array}{l}\text { G20 } \\
\text { G35 }\end{array}$ & $\begin{array}{c}c c . \dagger \\
0.002 \\
0.001 \\
0.002 \\
0.001\end{array}$ & \begin{tabular}{|c|} 
min. \\
29 \\
41 \\
38 \\
55
\end{tabular} & $\begin{array}{l}\text { min. } \\
15 \\
19.5 \\
15 \\
19.5\end{array}$ & $\begin{array}{r}17.5 \\
14.1 \\
8.5 \\
6.6\end{array}$ & $\begin{array}{c}\text { per cent } \\
15.8 \\
7.6\end{array}$ \\
\hline R. R. & 113 & $\begin{array}{l}\text { G20 } \\
\text { G35 }\end{array}$ & $\begin{array}{l}0.002 \\
0.001 \\
0.002 \\
0.001\end{array}$ & $\begin{array}{l}48 \\
67 \\
51 \\
81\end{array}$ & $\begin{array}{l}20.4 \\
30.2 \\
20.4 \\
30.2\end{array}$ & $\begin{array}{l}21 \\
18 \\
17.5 \\
9.0\end{array}$ & $\begin{array}{l}19.5 \\
13.2\end{array}$ \\
\hline I. G. & 72 & $\begin{array}{l}\text { G20 } \\
\text { G35 }\end{array}$ & $\begin{array}{l}0.002 \\
0.001 \\
0.002 \\
0.001\end{array}$ & $\begin{array}{l}38 \\
50 \\
48 \\
63\end{array}$ & $\begin{array}{l}21.8 \\
28.2 \\
21.8 \\
28.2\end{array}$ & $\begin{array}{r}25.0 \\
22.0 \\
13.0 \\
7.0\end{array}$ & $\begin{array}{l}23.5 \\
10.0\end{array}$ \\
\hline R. R. & 112 & G15 & $\begin{array}{l}0.001 \\
0.0005\end{array}$ & $\begin{array}{l}54 \\
65\end{array}$ & $\begin{array}{l}30.2 \\
43.6\end{array}$ & $\begin{array}{l}31.2 \\
39.4\end{array}$ & 35.3 \\
\hline
\end{tabular}

* See footnote 4.

† Solution containing 0.20 gram Fraction $I$ in 67 cc. physiological saline. This volume was used since it represents the volume of citrated plasma from which the 0.2 gram of Fraction I was derived.

TABLE III

Antihemophilic potency of plasma protein fraction precipitated by $\mathrm{CO}_{2}$ at $\mathrm{pH} 5.74$

Experiment 1

Test subject R. R. Clotting time, 87 minutes

\begin{tabular}{c|c|c}
\hline Fraction * tested & Cl. t. & $\begin{array}{c}\text { Antihemo- } \\
\text { philic } \\
\text { activity }\end{array}$ \\
\hline & min. & per cent \\
I. Parent plasma & 29 & 100 \\
II. $\mathrm{CO}_{2}$ precipitate & 29 & 100 \\
III. $\mathrm{CO}_{2}$ supernatant & 63 & 14 \\
IV. Repeat precipitation of II & 70 & 8 \\
with CO & & 16 \\
V. Supernatant of IV & 61 & 16 \\
\hline
\end{tabular}

Experiment 2

Test subject R. R. Clotting time, 87 minutes

I. Parent plasma

fII. $\mathrm{CO}_{2}$ precipitate

III. $\mathrm{CO}_{2}$ supernatant

\begin{tabular}{r|r}
25 & 100 \\
23 & 105 \\
60 & 13
\end{tabular}

* To 2 cc. of hemophilic blood was added an amount of material derived from $0.001 \mathrm{cc}$. of plasma in a volume of 0.1 cc.

+ An amount of this material (about 500 mgm.) derived from $90 \mathrm{cc}$. of plasma was given intravenously to the same patient. Three minutes after injection the clotting time was reduced from 87 to 13 minutes; $1 \frac{1}{2}$ hours later the clotting time was 22 minutes, and 20 hours later it was 44 minutes. About $\frac{1}{2}$ hour after injection the patient felt hot all over. This, the only untoward symptom, disappeared in 5 minutes. 


\section{Determination of the anti-hemophilic potency of certain plasma fractions}

The coagulation-accelerating property of plasma fractions can be assayed by comparing their antihemophilic activity with the parent plasma from which they were derived or with the mean activity of many plasmas. The results of illustrative examples of experiments in which this was done are given in Tables II and III. Samples of plasma Fraction $I^{4}$ were dissolved in a volume of physiological saline equal to that of the plasma from which the fraction was derived. A dilution of this was made with sufficient saline so that $0.1 \mathrm{cc}$. of the final dilution would contain an amount of antihemophilic material comparable in activity to no more than $0.001 \mathrm{cc}$. of plasma. With Fraction I it was impossible to compare the activity with that of the parent plasma since the latter was not available. Accordingly, its potency was calculated in terms of per cent of the mean potency of normal plasma.

Another plasma protein fraction (Table III) was prepared by $\mathrm{CO}_{2}$ saturation of citrated plasma diluted 1 to 10 (by volume) with distilled water. Fractionation was carried out at 0 to $5^{\circ} \mathrm{C}$., and the $\mathrm{pH}$ after saturation was 5.74. A few droplets of caprylic alcohol were added to prevent foaming. The precipitate, separated from the supernatant by centrifugation, was redissolved in a volume of 1.5 per cent sodium chloride solution one-tenth the original volume of plasma. To an aliquot sample was added 9 volumes of physiological saline. Sufficient solid sodium chloride was added to the supernatant to make it isotonic. A sample of the parent plasma, kept beside the material being fractioned, the plasma precipitate, and the supernatant were tested simultaneously against hemophilic blood.

The results indicate that several samples of Fraction I contained only 8 to 35 per cent of the antihemophilic activity of average plasma. On the other hand, the antihemophilic principle in normal plasma was quantitatively precipitated by $\mathrm{CO}_{2}$ under the above conditions. The precipitate was also active in vivo. Re-precipitation with $\mathrm{CO}_{2}$ resulted in large losses of antihemophilic potency.

\footnotetext{
4 Obtained through the courtesy of Dr. John T. Edsall, Dept. of Physical Chemistry, Harvard Medical School, from the Mass. State Division of Biologic Laboratories.
}

\section{DISCUSSION}

The cardinal disturbance in hemophilia is the retarded coagulation of hemophilic blood. Both the explanation of this phenomenon and the mechanism whereby normal plasma rectifies it are still unknown. Accordingly, the quantitative relationships observed by us between the addition of normal plasma to hemophilic blood and the clotting time of such mixtures must remain empiric.

Extremely minute amounts of plasma have a profound effect in accelerating the coagulation of hemophilic blood. As the amount of plasma is increased and the coagulation time approaches normal the increment in further reduction of the clotting time becomes increasingly less until it is no longer measurable. From inspection of the curves (Figures 1 and 2) it is obvious that differences in antihemophilic activity of between 0.0005 and $0.001 \mathrm{cc}$. of normal plasma are reflected by greater differences in clotting time than between 0.001 and $0.002 \mathrm{cc}$. when these volumes of plasma are added to $2 \mathrm{cc}$. of hemophilic blood. Clot acceleration induced by $0.002 \mathrm{cc}$. is almost maximal. The effects of $0.003,0.004$, and $0.005 \mathrm{cc}$. or more are practically indistinguishable from that of 0.002 cc. since the differences between the acceleration of coagulation induced by each are almost within the limits of accuracy of the method.

A clear realization of this is essential in studies on the antihemophilic clot-promoting moiety of human plasma or of other biologic sources. Unfortunately most of the reported investigations are based upon methods in which the clot-promoting effects of no less than $0.01 \mathrm{cc}$. of plasma, or its equivalent, are observed. Under such conditions losses in antihemophilic activity incurred in plasma fractionation procedures may have escaped detection, and erroneous conclusions may have been drawn.

Clearly the relationships indicated in Figures 1 and 2 are empirical observations which hold only between 2 limits. The one is imposed by the clotting time of hemophilic blood to which no normal plasma has been added and the sensitivity of the method in detecting acceleration in coagulation consequent to the addition of infinitesimally small amounts of normal plasma. Increasing the relative amount of normal plasma in the plasma-hemophilic blood mixture results in progressively 
greater overall reduction in coagulation time until the relatively normal range is reached asymptotically. This is the other limit in the relationship.

The configuration of the curves throws little light on the nature of the antihemophilic principle. Since the curves relating the clotting time of hemophilic blood to the amount of plasma added to it (Figure 1) resemble in shape the curves relating the activities of thrombin, prothrombin, and thromboplastin to their concentrations (15), it would appear that normal plasma restores to hemophilic blood normal coagulation processes involving some or all of these elements. That the effects are not referable to the addition of thrombin per se is obvious since plasma contains no thrombin. Prothrombin also cannot be implicated since prothrombin-free plasma retains antihemophilic activity (16). There is, furthermore, no evidence of a quantitative or qualitative prothrombin defect in hemophilia (8). Whether one prefers to label the antihemophilic moiety "plasma thromboplastin," as did Howell (17), or "globulin substance" as does Taylor et al. $(3,12)$ is academic since, until more is known regarding its physiological and biochemical properties, we can refer to it only through its effects on hemophilic blood.

The shape of the curves tells us little regarding the dynamics of the reaction between normal plasma and hemophilic blood. The linear nature of the logarithmic relationship does, however, indicate the reaction to be of an order higher than unimolecular. This curve, by being easily expressed mathematically, lends itself readily to calculation of the clotting time expected of any given normal plasma-hemophilic blood mixture. Contrariwise, the amount of normal plasma, or its antihemophilic equivalent, in such a mixture may be computed from its coagulation time. The value of this relationship is apparent in studies aimed at separation and purification of the antihemophilic principle of normal plasma, and elucidation of its biochemical and physiological properties.

Besides being of considerable clinical interest and significance the constancy of this relationship between clotting time and the amount of normal plasma is also useful. Since the effect on the coagulation of hemophilic blood is the only property by which the antihemophilic principle can now be measured, a well standardized hemophiliac can provide a readily available source of test material for quantitative studies. Furthermore, the pattern of his reaction remains unaffected by prophylactic treatment with plasma.

It should not be inferred from this that the coagulation time of any particular hemophiliac remains constant. That the clotting time may fluctuate considerably from time to time is well known. Should this occur the patient can be readily restandardized. Furthermore, as can be seen from our data, an extremely minute alteration in the amount of antihemophilic principle present in a fixed volume of hemophilic blood will produce a profound change in coagulation time in the steep part of the curve where coagulation times are greatest. Thus, for example, subject T. K. (Figure 1) has a clotting time which has spontaneously varied from 65 to 90 minutes. Although this discrepancy appears large it represents the activity of an extremely minute amount of antihemophilic principle in this range of the curve, which, if disregarded, introduces a negligible error.

It should be pointed out that acceleration of the coagulation of hemophilic blood is not an effect produced exclusively by the antihemophilic principle of plasma. Other plasma or tissue derivatives are also effective in this regard. Small amounts of tissue thromboplastin, or of thrombin, added to hemophilic blood will speed its coagulation. Extremely minute contamination of hemophilic blood with tissue juice, as can occur in unsuccessful venipuncture, will give erroneously low, if not normal, coagulation times (2), presumably due to tissue thromboplastin. Other agents capable of promoting the coagulation of hemophilic blood are certain proteolytic enzymes $(18,19)$. Accordingly, it is necessary to exclude, by suitable tests, the possibility that the clot-promoting effect of any biologic preparation is referable to any of the above mentioned substances.

Attention should be called to certain other advisable precautions and refinements in technique which would undoubtedly enhance the accuracy of the method. Our failure to recognize them early in the course of this study probably accounts in part for the substantial size of the standard deviation of normal plasma:

1. Accurate delivery of measured amount of hemophilic blood. Undoubtedly, a certain degree of inaccuracy arises from difficulty in placing ex- 
actly $2.0 \mathrm{cc}$. of hemophilic blood in the clotting-time tube, particularly when large numbers of determinations are being made simultaneously and blood must be delivered rapidly from a 50-cc. syringe. We have found that, even when care is exercised, up to $\mathbf{1 5}$ per cent too much or too little blood may be added, which may result in errors of this magnitude. This can be obviated by using graduated clotting-time tubes and by filling with blood exactly to the $2.1 \mathrm{cc}$. mark $(0.1 \mathrm{cc}$. of test material or saline having first been added) or by estimating the $2 \mathrm{cc}$. of blood and subsequently recording the exact amount by reading it off from the calibrated tube. Due correction can then be applied.

2. Red cell hemolysis. From observations we have made, to be reported in a subsequent communication, we have found that hemolysis of red cells, both normal and hemophilic, liberates a substance which will hasten the coagulation of hemophilic blood. The material is probably related to cephalin and exhibits thromboplastic activity. Accordingly, hemolysis in the drawing of hemophilic or normal blood should be avoided as much as possible.

3. Errors arising from admixture of tissue juice to blood samples. The invalidation of tests in which hemophilic blood is drawn by venipunctures which are not immediately successful has been mentioned. Similarly, in the drawing of normal blood for standardization of a particular hemophiliac, care should be exercised that the donor's vein be entered by "primary intention" in order to exclude tissue juice in test samples.

4. Errors arising from delay in completing experiments. The antihemophilic principle of normal plasma deteriorates quite rapidly in liquid plasma (20). The lability is especially marked in whole blood. Accordingly, substantial errors may arise from delay in separating the plasma from the cellular blood components and/or delay in running the experiments after the plasma has been obtained.

From our assay of the antihemophilic potency of some specimens of Fraction I of plasma, it appears that most of the antihemophilic activity had been lost in their preparation. Three different samples of this fraction exhibited only about 20,10 , and 35 per cent of the potency of normal plasma. The loss may only be apparent, and it may in part be attributable to low potencies of the parent plasmas resulting from deterioration consequent to unavoidable delays in processing. Some loss incurred in fractionation is, however, indicated by the appearance of clot-promoting activity in Fractions II and III (12).

There is remarkably little information in the literature concerning the antihemophilic potency of Fraction I and other plasma protein fractions, especially as compared with the original plasmas from which they were derived. From the most recent publication in this regard, by Taylor et al. (12), it would appear that Fraction I contains most of the antihemophilic activity to be found in plasma.

It is possible that the samples of Fraction I tested by these investigators was more potent than those assayed by us. Since, however, they tested no less than that amount of Fraction $\mathrm{I}^{3}$ derived from approximately $0.01 \mathrm{cc}$. of plasma it is possible that the discrepancy in reported potency of this plasma protein fraction may be referable to their use of a less sensitive range in the measurement of antihemophilic activity.

That the antihemophilic component of normal plasma is precipitated practically quantitatively by $\mathrm{CO}_{2}$ saturation of diluted plasma, reported by others $(3,21)$ and confirmed by us, is of practical importance. The full activity of $100 \mathrm{cc}$. of plasma is contained in about $500 \mathrm{mgm}$. of this protein fraction. Five hundred mgm. of Fraction I, on the other hand, appear to contain the antihemophilic activity of only 13 to $60 \mathrm{cc}$. of plasma. The $\mathrm{CO}_{2}$ precipitated fraction would accordingly seem to be a better starting point for further purification of the antihemophilic principle than Fraction I.

The importance of comparing clot-promoting activity of plasma fractions with their parent plasmas, or, these being unavailable, with the mean activity of normal plasma has been referred to above. We feel that it is desirable, in plasma fractionation work, to consider normal plasma arbitrarily as a standard of reference. We propose that $0.001 \mathrm{cc}$. of plasma be designated as containing 1 unit of antihemophilic activity. This amount of plasma is selected arbitrarily because it also represents an amount of antihemophilic activity

B 0.1 cc. of $1 / 100$ dilution of a 4 per cent solution of Fraction I. Four grams of Fraction I are derived from 1000 cc. of plasma (10). 
which should not be exceeded in in vitro assay on hemophilic blood. On this basis relative degrees of purity and total yield of various plasma fractions can be readily expressed (Table IV).

TABLE IV

Comparative antihemophilic activity of 2 plasma protein fractions

\begin{tabular}{|c|c|c|c|}
\hline Plasma fraction & $\begin{array}{l}\text { Antihemo- } \\
\text { philic } \\
\text { activity } \\
\text { units* }\end{array}$ & \multicolumn{2}{|c|}{$\begin{array}{l}\text { Amount of antihemophilic } \\
\text { material obtainable from } \\
1 \text { liter of citrated plasma }\end{array}$} \\
\hline $\begin{array}{l}\text { Plasma } \\
\text { Fraction I } \\
\quad \text { G-35 } \\
\quad \mathrm{G}-20 \\
\quad \mathrm{G}-15 \\
\mathrm{CO}_{2} \text { precipitate }\end{array}$ & $\begin{array}{c}\text { per mgm. } \\
\text { of cotal } \\
\text { solids } \\
17 \\
30 \\
60 \\
120 \\
200\end{array}$ & $\begin{array}{c}\text { units } \\
1,000,000 \\
100,000 \text { to } 350,000\end{array}$ & $\begin{array}{c}\text { grams } \\
60 \\
4\end{array}$ \\
\hline
\end{tabular}

* One unit is defined as that amount of antihemophilic principle which accelerates the coagulation of $2 \mathrm{cc}$. of hemophilic blood to the same extent as $1 \mathrm{cu}$. $\mathrm{mm}$. of average fresh citrated human plasma.

As little as $0.5 \mu \mathrm{g}$. of the $\mathrm{CO}_{2}$ precipitated fraction added to $2 \mathrm{cc}$. of hemophilic blood will accelerate its coagulation appreciably. The clotpromoting principle, which in its crude form is now active in a dilution of about 1 part in 2.2 million, will probably be found to exhibit much higher activity when it is purified further since the $\mathrm{CO}_{2}$ precipitated fraction undoubtedly contains some fibrinogen and prothrombin $(3,21,22)$.

\section{SUMMARY AND CONCLUSIONS}

1. The quantitative relationship between the coagulation time of shed hemophilic blood and the amount of normal plasma added to it is described. It provides the basis for a method of assaying the antihemophilic principle of plasma.

2. This relationship was peculiar to, and constant in, each of 4 hemophiliacs studied òver a prolonged interval. It was unaffected by plasma therapy.

3. The antihemophilic activity of normal plasma is fairly uniform.

4. The clot-promoting principle of normal plasma is precipitated quantitatively from diluted plasma by saturation with $\mathrm{CO}_{2}$. The precipitate is active in a dilution of 1 part in 2.2 million.

5. Three samples of plasma protein Fraction I were found to contain about 10,20, and 30 per cent, respectively, of the antihemophilic potency of whole plasma.
6. It is proposed that whole normal plasma be considered a reference standard in studies aimed at concentration and purification of its antihemophilic principle. One antihemophilic unit is defined.

\section{BIBLIOGRAPHY}

1.Sahli, H., Weitere Beiträge zur Lehre von der Hämophilie. Deutsch. Arch. f. klin. Med., 1910, 99, 518.

2. Patek, A. J., Jr., and Stetson, R. P., Hemophilia. I. The abnormal coagulation of the blood and its relation to the blood platelets. J. Clin. Invest., 1936, 15, 531.

3. Patek, A. J., Jr., and Taylor, F. H. L., Hemophilia. II. Some properties of a substance obtained from normal human plasma effective in accelerating the coagulation of hemophilic blood. J. Clin. Invest., 1937, 16, 113.

4. Bendien, W. M., and van Creveld, S., Investigations on Hemophilia. II. Maandschr. v. kindergeneesk, 1937, 6, 186.

5. Lozner, E. L., and Taylor, F. H. L., The coagulation defect in hemophilia; studies of the clot-promoting activity associated with plasma euglobulin in hemophilia. J. Clin. Invest., 1939, 18, 821.

6. Laki, K., The autocatalytic formation of thrombin and the clotting defect of hemophilic blood. Studies from the Institute of Medical Chemistry, University Szeged, Hungary, 1943, III, 5.

7. Minot, G. R., Davidson, C. S., Lewis, J. H., Tagnon, H. J., and Taylor, F. H. L., The coagulation defect in hemophilia. The effect in hemophilia of the parenteral administration of a fraction of the plasma globulins rich in fibrinogen. J. Clin. Invest., 1945, 24, 704

8. Lewis, J. H., Davidson, C. S., Minot, G. R., Soulier, J. P., Tagnon, H. J., and Taylor, F. H. L., Chemical, clinical, and immunological studies on the products of human plasma fractionation. XXXII. The coagulation defect in hemophilia. An in vitro and in vivo comparison of normal and hemophilic whole blood, plasma, and derived plasma protein fractions. J. Clin. Invest., 1946, 25, 870.

9. Chargaff, E., and West, R., The biological significance of the thromboplastic protein of blood. J. Biol. Chem., 1946, 166, 189.

10. Cohn, E. J., Oncley, J. L., Strong, L. E., Hughes, W. L., Jr., and Armstrong, S. H., Jr., The characterization of the protein fractions in human plasma. J. Clin. Invest., 1944, 23, 417.

11. Cohn, E. J., Strong, L. E., Hughes, W. L., Jr., Mulford, D. J., Ashworth, J. N., Melin, M., and Taylor, F. H. L., Preparation and properties of serum and plasma proteins. IV. A system for the separation into fractions of the protein and lipoprotein components of biological tissues and fluids. J. Am. Chem. Soc., 1946, 68, 459. 
12. Taylor, F. H. L., Davidson, C. S., Tagnon, H. J., Adams, M. A., MacDonald, A. H., and Minot, G. R., Studies in blood coagulation. The coagulation properties of certain globulin fractions of normal human plasma in vitro. J. Clin. Invest., 1945, 24, 698.

13. Pohle, F. J., and Taylor, F. H. L., The coagulation defect in hemophilia. The effect in hemophilia of intramuscular administration of a globulin substance derived from normal human plasma. J. Clin. Invest., 1937, 16, 741.

14. Alexander, B., and Landwehr, G., Studies on Hemophilia. I. The control of hemophilia by repeated infusions of normal human plasma. J. A. M. A. (In press).

15. Quick, A. J., The Hemorrhagic Diseases and the Physiology of Hemostasis. Charles C. Thomas, Springfield, Illinois, 1942, pp. 16, 37, 71.

16. Lewis, J. H., Soulier, J. P., and Taylor, F. H. L., Chemical, clinical and immunological studies on the products of human plasma fractionation. XXXIII. The coagulation defect in hemophilia:
The effect in vitro and in vivo on the coagulation time in hemophilia of a prothrombin and fibrinogenfree normal plasma and its derived protein factions. J. Clin. Invest., 1946, 25, 876.

17. Howell, W. H., Hemophilia. Bull. New York Acad. Med., 1939, 15, 3.

18. Eagle, H., and Harris, T. N., Studies in blood coagulation. V. The coagulation of blood by proteolytic enzymes (trypsin, papain). J. Gen. Physiol., 1937, 20, 543.

19. Tyson, T. L., and West, R., Effect of trypsin on the clotting of the blood in hemophilia. Proc. Soc. Exper. Biol. \& Med., 1937, 36, 494.

20. Alexander, B., Studies on hemophilia. III. Some biochemical and physiological properties of the antihemophilic principle of normal human plasma. In preparation.

21. Addis, T., The pathogenesis of hereditary hemophilia.

- J. Path. and Bact., 1911, 15, 427.

22. Eagle, H., Studies on blood coagulation. I. The role of prothrombin, and of platelets in the formation of thrombin. J. Gen. Physiol., 1935, 18, 531. 